\title{
Effect of Activities of Daily Living on Self-Care Agency in Individuals with Type 2 Diabetes
}

\author{
Neslihan Istek ${ }^{1}$, Papatya Karakurt ${ }^{2 *}$ \\ ${ }^{1}$ Department of Patient Care at Home, Pazar Vocational School, Gaziosmanpaşa University, Tokat, Turkey \\ ${ }^{2}$ School of Health, Erzincan University, Erzincan, Turkey \\ Email: neslihan5824@gmail.com, *papatyademirci@hotmail.com
}

How to cite this paper: Istek, N. and Karakurt, P. (2016) Effect of Activities of Daily Living on Self-Care Agency in Individuals with Type 2 Diabetes. Journal of Diabetes Mellitus, 6, 247-262.

http://dx.doi.org/10.4236/jdm.2016.64026

Received: May 9, 2016

Accepted: October 8, 2016

Published: October 11, 2016

Copyright (c) 2016 by authors and Scientific Research Publishing Inc. This work is licensed under the Creative Commons Attribution International License (CC BY 4.0).

http://creativecommons.org/licenses/by/4.0/

\begin{abstract}
Background: Diabetes mellitus continues to be a global health problem with increasing importance across the world by affecting the activities of daily living and self-care ability of patients due to its incidence and troubles caused by it. The present study aims at determining the effect of activities of daily living of patients with type 2 diabetes mellitus on their self-care agency. Methods: The population of this descriptive study consisted of patients with type 2 diabetes mellitus who were being treated at the internal medicine clinic of a provincial state hospital between July 2014 and November 2015 and its sample consisted of 150 diabetic patients who volunteered to take part in the study and who were open to communication. A personal information form, the Activities of Daily Living (ADL) Scale, the Instrumental Activities of Daily Living (IADL) Scale and the Self-Care Ability Scale (CAS) were used as data collecting tools. The data were analyzed using descriptive statistics (numbers, percentages, mean, standard deviation, mean rank and frequencies), the Shapiro-Wilk, KruskalWallis Variance Analysis, Mann-Whitney U test and Cronbach's alpha formula and correlation analysis. Results: Approximately $97.3 \%$ of the patients with type 2 diabetes stated that they were independent in ADL and $75.3 \%$ of them in IADL. The patients' mean self-care ability score was found to be $83.85 \pm$ 17.87 ADL and IADL were found to be affected by age, marital status, education, duration of disease, willingness to receive further education, and presence of another disease besides diabetes. There was a significant correlation between the self-care agency score and marital status, education, duration of disease, willingness to receive further education, presence of another disease besides diabetes, regular checking of blood sugar and compliance with diet. A significant positive correlation was found between the patients' activities of daily living and their self-care agency. Conclusion: The patients' activities of daily living were found to affect their self-care agency. The personal and disease-related characteristics of patients should be identified so that their self-care behaviors can be increased.
\end{abstract}

${ }^{*}$ Corresponding author. 


\section{Keywords}

Diabetes Mellitus, Activities of Daily Living, Self-Care Agency, Nursing

\section{Introduction}

Diabetes has become an increasingly important health problem across the world today due to its frequency and the problems arising from it. With the rapid changes in life styles, the prevalence of type 2 diabetes in particular increases rapidly in the entire developed and developing countries and studies demonstrate that the prevalence of type 2 diabetes also increases in childhood. Approximately $90 \%$ of all diabetic persons suffer from type 2 diabetes. One of the major reasons for this increase is the growing obesity and physical inactivity resulting from life style changes that are induced by population growth, aging and urbanization [1]-[3].

Diabetes influences the lives of individuals and families in many ways and as a result causes them to experience difficulties in performing their activities of daily living. For this reason, while diabetic persons engage in activities of daily living, they also need to relate these activities to their self-care [4]. In a study made with older patients with type 2 diabetes, it was found that the patients experienced inability in their activities of daily living and they tried to improve their physical inabilities by using assistive devices [5]. It was shown in some studies made with subjects with various chronic diseases [6]-[8] that most of them were in dependent when carrying out both their activities of daily living and instrumental activities of daily living, whereas some other studies found that they were either semi-dependent or dependent [9]-[11].

Diabetes is a chronic disease requiring constant medical care and self-care due to its acute and chronic complications [3] [12]. Self-care is defined as assuming and fulfilling that part of the responsibility that rests with the person in concern to protect and improve his/her health. The individual's self-care activities play a major role in controlling the blood glucose level in diabetic patients [13]. Studies with diabetic patients have shown that patients' behaviors affect self-care and although patients are aware of the importance of self-care in managing diabetes, they find it difficult to fully comprehend and implement self-care [14]-[17]. In the studies made with patients with type 2 diabetes, the mean scores of self-care agency of the patients turned out to be low or a little higher than moderate level [5] [18]-[20].

Since diabetes requires lifelong care and follow-up, self-care is very important in its treatment. Nurses, who are aware of the significance of patients' self-care in their treatment, work in collaboration with patients in the process of acquiring the knowledge, skills and behavioral changes necessary for self-care and play an effective role in improving patients' quality of life and decreasing their dependence on medication [21] [22].

This study was conducted to determine the effect of activities of daily living of patients with type 2 diabetes on their self-care agency. 


\section{Materials and Methods}

\subsection{Subject Population and Sample Size}

The population of this descriptive study consisted of 170 patients with type 2 diabetes who were hospitalized and treated in the Internal Medicine Clinic of Kastamonu Dr. Münif Islamoğlu State Hospital between November 2014 and August 2015. No sampling was attempted and the study was concluded with 150 diabetic subjects as adequate communication could not be established with 8 patients and 12 patients did not agree to participate in the study. It was estimated that a sample of 150 patients would be sufficient to detect a power of 0.9912 with a significant difference between the scores, with a Type I error of 0.05 .

\subsection{Data Collecting Forms Used in the Study}

The study data were collected using a Personal Data Form, the Katz Index of Independence in Activities of Daily Living (Katz ADL), the Lawton-Brody Instrumental Activities of Daily Living Scale (IADL) and the Self-Care Agency Scale (SCAS).

Personal Data Form: The form was prepared by the investigator by way of a literature search [5]-[9] [15]-[20] and it included 6 questions relating to the socio-demographic characteristics of the patients with type 2 diabetes (age, gender, education, marital status, employment and income) and 10 questions relating to their type 2 diabetes (duration of disease, regular medicine use, compliance with diet, etc.), making a total of 16 questions.

KATZ Index of Independence in Activities of Daily Living (KATZ ADL): Developed by Katz and associates, the index measures the degree of dependence in self-care activities such as eating, dressing, having a bath, mobility, continence, and using the bathroom. An individual is scored 3 if he/she performs his/her activities of daily living independently, 2 if performs them with help, and 1 if altogether fails to perform them. According to KATZ ADL, scores of 0 - 6 are assessed as dependent, 7 - 12 as semi-dependent and $13-18$ as independent [23]. The alpha value was found as 0.79 in the present study.

Lawton-Brody Instrumental Activities of Daily Living Scale (IADL): The scale consists of questions on using a phone, preparing meals, shopping, doing daily chores, washing laundry, using vehicles, taking medicines and money management. An individual is scored 3 if he/she performs these activities independently, 2 if performs them with help, and 1 if altogether fails to perform them. According to IADL, scores of 0 - 8 are assessed as dependent, $9-16$ as semi-dependent and $17-24$ as independent [24]. The alpha value was found as 0.86 in this study.

Self-Care Agency Scale (SCAS): Consisting of 43 items, the scale was developed by Kearney and Fleicher (1979) to measure the ability of a person to look after him/herself or in other words his/her self-care agency. The scale was adapted by Nahcivan in 1993 for Turkish adolescences and reduced to 35 items. Each statement in the scale is scored from 0 to 4, giving 0 to "It does not define me at all", 1 to "It does not define me very much", 2 to "I have no idea", 3 to "It slightly defines me" and 4 to "It defines me very 
well". In the Turkish version of the scale, 8 items (items 3, 6, 9, 13, 19, 22, 26 and 31) are assessed negatively and a reverse scoring is used. This scale is the most widely used scale among the scales developed in this subject after the concept of self-care agency was introduced. The scale has 35 items that focus on how much people are interested in their self-care activities and how they assess themselves. The maximum score obtainable from the scale is 140 . Higher points obtained from SCAS show that the person is independent and self-sufficient in performing his/her self-care [25] [26]. Points approaching " 0 " show that the self-care agency scores is declining and points approaching " 140 " that the score is rising. Nahcivan reported that the alpha value of the scale was 0.89 [27]. Its alpha value turned out to be 0.90 in this study.

\subsection{Data Collection}

The study data were collected using the personal data form, Katz ADL, IADL and SCAS. The data collection forms were filled out by the investigator during the one-toone interviews held with the patients who were hospitalized in the Internal Medicine Clinic with a diagnosis of type 2 diabetes and who met the sampling criteria; necessary explanations were provided to the patients and the completion of forms took about 25 30 minutes.

\subsection{Data Assessment}

The data obtained from the study were evaluated electronically using the appropriate statistical analyses in the SPSS (Statistical Package for Social Sciences) 22.0software. The descriptive statistics are given as numbers, percentages and means. The ShapiroWilk analysis was run to see if the data had a normal distribution and since they did not have a normal distribution a decision was made to perform nonparametric analyses. These analyses were the Mann Whitney U test, Kruskal Wallis H test, Dunnet T3 Post Hoc test and Correlation Analysis tests. The significance level was set at $\mathrm{p}<0.05$.

\subsection{Ethical Concerns of the Study}

To be able to conduct the study, after obtaining the approval of the Ethics Committee of Erzincan University, written permission was obtained from the General Secretariat of the Association of Public Hospitals in Kastamonu. Before commencing the study, the subjects to take part in the study were explained about the purpose, length and implementation stage of the study and the Informed Consent Principle was adhered to. Verbal consents were obtained from the subjects and those who volunteered were included in the study.

\section{Results}

Of the subjects with type 2 diabetes who participated in the study $97.3 \%$ were independent as per Katz ADL and $24.7 \%$ were semi-dependent and $75.3 \%$ independent as per IADL. The mean score of Katz ADL was $16.93 \pm 1.82$ and that of IADL was $19.43 \pm$ 4.36 . 
As seen in Table 1, there is a correlation between the marital status and the mean SCAS scores of the subjects with type 2 diabetes. As a result of the Dunnet T3 Post Hoc test that was run to see the origin of this correlation, the bachelors were observed to have higher self-care agency scores than those who were married or divorced/widowed, which showed that single subjects had better self-care behaviors.

Table 1. Comparison of mean SCAS scores of diabetic subjects with respect to their socio-demographic characteristics $(n=150)$.

\begin{tabular}{|c|c|c|c|}
\hline $\begin{array}{c}\text { Socio-Demographic } \\
\text { Characteristics }\end{array}$ & Number & $\%$ & Mean Rank Self-Care Agency Score \\
\hline \multicolumn{4}{|c|}{ Age } \\
\hline 39 and $\downarrow$ & 4 & 2.7 & 115.38 \\
\hline $40-49$ & 18 & 12.0 & 77.47 \\
\hline $50-59$ & 32 & 21.3 & 76.17 \\
\hline $60-69$ & 53 & 35.3 & 77.81 \\
\hline 70 and $\uparrow$ & 43 & 28.7 & 67.62 \\
\hline \multicolumn{3}{|c|}{ Test and significance } & $\begin{array}{c}\mathrm{KW}=4.984 \\
\mathrm{p}=0.289\end{array}$ \\
\hline \multicolumn{4}{|c|}{ Gender } \\
\hline Female & 97 & 64.7 & 70.43 \\
\hline Male & 53 & 35.3 & 84.77 \\
\hline \multicolumn{3}{|c|}{ Test and significance } & $\begin{array}{c}\mathrm{z}=-1.933 \\
\mathrm{p}=0.053\end{array}$ \\
\hline \multicolumn{4}{|c|}{ Marital Status } \\
\hline Married & 114 & 76.0 & 81.17 \\
\hline Single & 2 & 1.3 & 116.25 \\
\hline Divorced/Widowed & 34 & 22.7 & 54.09 \\
\hline \multicolumn{3}{|c|}{ Test and significance } & $\begin{array}{c}\mathrm{KW}=11.968 \\
\mathrm{p}=0.003^{* *}\end{array}$ \\
\hline \multicolumn{4}{|c|}{ Education } \\
\hline Illiterate & 60 & 40.0 & 62.88 \\
\hline Literate/Primary School & 60 & 40.0 & 75.09 \\
\hline Secondary School & 17 & 11.3 & 93.76 \\
\hline High School-University & 13 & 8.7 & 111.77 \\
\hline \multicolumn{3}{|c|}{ Test and significance } & $\begin{array}{c}\mathrm{KW}=17.148 \\
\mathrm{p}=\mathbf{0 . 0 0 1}\end{array}$ \\
\hline \multicolumn{4}{|c|}{ Employment } \\
\hline Employed & 20 & 13.3 & 86.05 \\
\hline Unemployed & 130 & 86.7 & 73.88 \\
\hline \multicolumn{3}{|c|}{ Test and significance } & $\begin{array}{c}\mathrm{U}=1089.00 \\
\mathrm{p}=0.243\end{array}$ \\
\hline \multicolumn{4}{|c|}{ Income } \\
\hline Income less than expenses & 30 & 20.0 & 66.90 \\
\hline Income equal to expenses & 99 & 66.0 & 78.58 \\
\hline Income more than expenses & 21 & 14.0 & 73.29 \\
\hline \multicolumn{3}{|c|}{ Test and significance } & $\begin{array}{c}\mathrm{KW}=1.727 \\
\mathrm{p}=0.422\end{array}$ \\
\hline
\end{tabular}

${ }^{*} \mathrm{p}<0.05 ;{ }^{* *} \mathrm{p}<0.01$. 
There is also a significant correlation between education status and the mean SCAS scores of the subjects with type 2 diabetes. As a result of the Dunnet T3 Post Hoc test that was run to see the origin of this correlation, those who were graduates of high school/university were seen to have higher self-care agency scores than those who were illiterate or literate-private school graduates. Thus, the level of education was effective in improving self-care behaviors.

There were no correlations between the mean SCAS scores of the subjects and their age, gender, employment or income.

Table 2 shows the mean self-care agency scores of the subjects with respect to the characteristics of their diseases. There is a correlation between the duration of disease and the mean SCAS scores of the subjects with type 2 diabetes who were included in the study. As a result of the Dunnet T3 Post Hoc test that was run to see the origin of this correlation, those who had the disease for less than a year, 1 - 5 years and $6-10$ years were seen to have higher self-care agency scores than those who had the disease for 11 years and over. Longer durations of disease led to a decline in self-care behaviors.

A significant correlation was found between the willingness to receive further education on diabetes and the mean self-care agency scores of the subjects with type 2 diabetes. Those who were willing to receive further education had higher self-care agency scores than those who were unwilling to do so.

There was a significant correlation between the awareness about disease complications and the mean SCAS scores of the diabetic subjects. Those who were aware of disease complications had higher self-care agency scores than those who were unaware of them.

There was a correlation between the presence of other diseases besides diabetes and the mean SCAS scores of the subjects with type 2 diabetes who were included in the study. Those who had no other disease besides diabetes had higher SCAS scores than those who had other diseases.

There was a significant correlation between the regular checking of blood sugar and the mean SCAS scores of the subjects. As a result of the Dunnet T3 Post Hoc test that was run to see the origin of this correlation, those who had their blood sugar checked regularly were seen to have higher self-care agency scores than those who failed to do so.

There was a correlation between the compliance with diet and the mean SCAS scores of the subjects with type 2 diabetes. Those who adhered to their diets had higher self-care agency scores than those who failed to do so.

There was no significant correlation between the mean self-care agency scores of the diabetic subjects and the method of treating diabetes, frequency of check-ups, previous education on diabetes or regular use of medication (Table 3 ).

A significant positive correlation was found between activities of daily living and self-care agency. As the level of independence of patients increased in their activities of daily living, their self-care agency behaviors also improved. 
Table 2. Comparison of mean SCAS scores of diabetic subjects with respect to characteristics of their diseases $(n=150)$.

\begin{tabular}{|c|c|c|c|}
\hline $\begin{array}{l}\text { Disease-Related } \\
\text { Characteristics }\end{array}$ & Number & $\%$ & Mean Rank Self-Care Agency Score \\
\hline \multicolumn{4}{|c|}{ Duration of Disease } \\
\hline Less than 1 year & 8 & 5.3 & 91.69 \\
\hline $1-5$ years & 35 & 23.3 & 85.89 \\
\hline $6-10$ years & 46 & 30.7 & 85.27 \\
\hline More than 11 years & 61 & 40.7 & 60.05 \\
\hline \multicolumn{3}{|c|}{ Test and significance } & $\begin{array}{l}\mathrm{KW}=13.162 \\
\mathrm{p}=0.004^{\star *}\end{array}$ \\
\hline \multicolumn{4}{|c|}{ Diabetes Treatment Method } \\
\hline Oral Anti-diabetics & 26 & 17.3 & 62.83 \\
\hline Insulin & 30 & 20.0 & 84.45 \\
\hline $\begin{array}{l}\text { Oral Anti-diabetics } \\
\text { previously; insulin now }\end{array}$ & 43 & 28.7 & 82.50 \\
\hline $\begin{array}{c}\text { Physical Exercise, } \\
\text { Diet and Oral Anti-diabetics }\end{array}$ & 16 & 10.7 & 77.47 \\
\hline $\begin{array}{l}\text { Oral Anti-diabetics } \\
\text { and insulin }\end{array}$ & 35 & 23.3 & 69.40 \\
\hline \multicolumn{3}{|c|}{ Test and significance } & $\begin{array}{c}\mathrm{KW}=6.989 \\
\mathrm{p}=0.221\end{array}$ \\
\hline \multicolumn{4}{|c|}{ Frequency of Diabetic Check-Up } \\
\hline When feeling ill & 95 & 63.3 & 72.79 \\
\hline Once a month & 17 & 11.3 & 83.47 \\
\hline Every 2 months & 9 & 6.0 & 70.44 \\
\hline Every 3 months & 16 & 10.7 & 95.38 \\
\hline Semi-annually & 8 & 5.3 & 64.94 \\
\hline Annually & 5 & 3.3 & 62.30 \\
\hline \multicolumn{3}{|c|}{ Test and significance } & $\begin{array}{c}\mathrm{KW}=5.350 \\
\mathrm{p}=0.375\end{array}$ \\
\hline \multicolumn{4}{|c|}{ Previous Education on Diabetes } \\
\hline Yes & 115 & 76.7 & 74.23 \\
\hline No & 35 & 23.3 & 79.69 \\
\hline \multicolumn{3}{|c|}{ Test and significance } & $\begin{array}{c}Z=-0.651 \\
\mathrm{p}=0.515\end{array}$ \\
\hline \multicolumn{4}{|c|}{ Willingness for Further Education } \\
\hline Yes & 81 & 54.0 & 83.70 \\
\hline No & 69 & 46.0 & 65.88 \\
\hline \multicolumn{3}{|c|}{ Test and significance } & $\begin{array}{c}\mathrm{z}=2.505 \\
\mathrm{p}=\mathbf{0 . 0 1 2 ^ { * }}\end{array}$ \\
\hline
\end{tabular}




\section{Continued}

\begin{tabular}{|c|c|c|c|}
\hline \multicolumn{4}{|c|}{ Awareness about Disease Complications } \\
\hline Yes & 79 & 52.7 & 85.95 \\
\hline No & 71 & 47.3 & 63.87 \\
\hline \multicolumn{3}{|c|}{ Test and significance } & 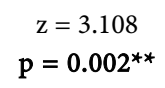 \\
\hline \multicolumn{4}{|c|}{ Presence of Other Diseases besides Diabetes } \\
\hline Yes & 124 & 82.7 & 71.81 \\
\hline No & 26 & 17.3 & 93.08 \\
\hline \multicolumn{3}{|c|}{ Test and significance } & $\begin{array}{l}U=1155.00 \\
p=0.023^{*}\end{array}$ \\
\hline \multicolumn{4}{|c|}{ Regular Use of Medication } \\
\hline Yes & 128 & 85.3 & 77.29 \\
\hline No & 22 & 14.7 & 65.07 \\
\hline \multicolumn{3}{|c|}{ Test and significance } & $\begin{array}{c}\mathrm{U}=1178.500 \\
\mathrm{p}=0.223\end{array}$ \\
\hline \multicolumn{4}{|c|}{ Regular Visits for Blood Sugar Checks } \\
\hline Yes & 52 & 34.7 & 89.37 \\
\hline No & 60 & 40.0 & 65.56 \\
\hline Sometimes & 38 & 25.3 & 72.22 \\
\hline \multicolumn{3}{|c|}{ Test and significance } & $\begin{array}{l}\mathrm{KW}=8.660 \\
\mathrm{p}=\mathbf{0 . 0 1 3 ^ { * }}\end{array}$ \\
\hline \multicolumn{4}{|c|}{ Compliance with Diet } \\
\hline Yes & 61 & 40.7 & 85.93 \\
\hline No & 89 & 59.3 & 68.35 \\
\hline \multicolumn{2}{|c|}{ Test and significance } & & $\begin{array}{l}\mathrm{z}=-2.436 \\
\mathrm{p}=\mathbf{0 . 0 1 5 ^ { * }}\end{array}$ \\
\hline
\end{tabular}

${ }^{*} \mathrm{p}<0.05 ;{ }^{* *} \mathrm{p}<0.01$.

Table 3. Correlation between ADL, IADL and SCAS $(n=150)$.

\begin{tabular}{ccc}
\hline ADL & \multicolumn{2}{c}{ SCAS r p } \\
\hline Katz ADL & 0.237 & $0.004^{*}$ \\
IADL & 0.673 & $0.000^{*}$ \\
\hline
\end{tabular}

${ }^{*} \mathrm{p}<0.01$.

\section{Discussion}

No significant correlation was found between the age and self-care agency of diabetic subjects. The results of many studies made with diabetic persons are similar to that of the present study [19] [20] [28] [29]. Although the patients were aware of the importance of self-care in managing diabetes, most of them seemed to experience difficulties in performing self-care. One of the reasons for this was reported to be aging [15]. The 
present study suggests that alongside personal characteristics, the disease-related characteristics can also be important in affecting the self-care agency.

There was no statistically significant correlation between the genders and self-care agency scores of the subjects. Similar to the results of this study, Gül et al. [19], Düzöz et al. [29], Yurtsever and Kuyutay [30], and Akyol and Karadakovan [31] have also found in their studies that gender does not have any impact on self-care.

According to Orem, a society is composed, to a large extent, of individuals, families and groups that share a common concern and interest in institutions that regulate and manage not only a common geographical area and the environment but also the life style [32]. There was a correlation between the marital status and mean self-care agency scores of the subjects with type 2 diabetes who were included in the study. Single patients were observed to have higher self-care agency scores than those who were married or divorced/widowed. In the study of Aksel [18] made with subjects with chronic diseases, there was also a significant correlation between marital status and self-care agency scores. Many other studies, however, found that marital status did not affect self-care agency scores [20] [29] [33] [34].

There was a significant correlation between the education status and mean self-care agency scores of the subjects with type 2 diabetes. The patients who were graduates of high school/university were seen to have higher self-care agency scores than those who were illiterate or literate-private school graduates. While some studies have found a significant correlation between education and mean self-care agency scores [35]-[37], the majority of studies have reported that there is no statistically significant correlation between them [18]-[20] [29] [34] [38]. We found that higher levels of education make a positive impact on the self-care behaviors of patients towards diabetes.

There was no significant correlation between the employment statuses of the subjects and their self-care agency scores. Similar to this result of our study, many other studies have also not found any significant correlation between employment and self-care agency [18] [29] [30] [31] [33].

We found that there was no significant correlation between the income statuses of the participants and their self-care agency scores. Many studies have also shown that income does not affect self-care agency [18] [33] [34]. However, a study made with diabetic patients found that patients with moderate income had higher self-care agency [17]. In another study, a statistically significant correlation was found between income and self-care agency scores [20].

There was a significant correlation between the duration of disease and mean selfcare agency scores of the subjects with type 2 diabetes who were included in the study. Those who had the disease for less than a year, 1 - 5 years and 6 - 10 years were seen to have higher self-care agency scores than those who had the disease for 11 years and over. Many studies have not found any significant correlation between the duration of disease and self-care agency score [18]-[20] [34]. In the study of Özkan and Durna [39] they made with diabetic patients, the subjects who had the disease for 0 - 5 years since diagnosis were found to have higher self-care agency scores. 
The diabetes treatment methods of the subjects with type 2 diabetes were found not to affect their self-care agency. Most of the patients used oral anti-diabetics previously and insulin at present. Similar to the result of our study, it was also found in another study that the diabetes treatment method did not affect self-care agency [20]. Another study showed that although patients were aware of the importance of self-care in managing diabetes, most of them found it difficult to implement self-care [15]. In type 2 diabetes, oral anti-diabetic medicines are used more commonly than insulin therapy [40] [41]. For diabetic individuals to be able to manage their diabetes in a successful manner, they should set out their targets and make daily decisions accordingly. The intervention strategies of diabetes educators should be improved to encourage diabetic persons to make decisions about their targets, therapeutic options and self-care behaviors and to assume the responsibility of their daily diabetic self-care in order to be effective in their own care [22]. Other characteristics of the disease are thought to be effective in managing diabetes in diabetic people.

The correlation between the frequency of diabetic check-ups and self-care agency score was found to be insignificant. Similar to our study result, no significant correlation was observed between the frequency of diabetic check-ups and self-care agency score in another study [18]. Regular follow-up should be an inseparable part of longterm management in a chronic disease like diabetes, but that is often neglected [42].

No significant correlation was found between previous education on diabetes and self-care agency score. Also in the study of Aksel (2010), no significant correlation was seen between previous education on the disease and self-care agency score [18]. Düzöz et al. [19] also did not find any statistically significant correlation between receiving educations and mean self-care agency score in their study they made with patients with type 2 diabetes. Another study, on the other hand, showed that patients who were less knowledgeable about diabetes had poorer self-care behaviors [17]. It was found in another study that patients who received education on self-care had better self-care behaviors [43]. Although it has been shown that effective self-care behaviors are associated with increased knowledge in improving diabetes [44] [45], we found in this study that previous education on diabetes did not have any impact on self-care agency.

A correlation was found between the willingness of patients with type 2 diabetes to receive further education and their mean self-care agency scores. Those who were willing to receive further education had higher self-care agency scores than those who were unwilling to do so. It was found in a study that although patients were aware of the importance of self-care in managing diabetes, most of them found it difficult to implement. One of the reasons for this was reported to be inadequate knowledge of diabetes [15]. In order for diabetic persons to perform self-care, they need educational, supportive and constructive nursing practices. Such practices include providing support and guidance, doing environmental arrangements and educating patients on disease treatment [46].

Diabetes and its complications put a great economic burden on patients, their families, healthcare systems and countries [2]. A correlation was found between the aware- 
ness about the disease complications and mean self-care agency scores of the diabetic subjects. Those who were aware of disease complications had higher self-care agency scores than those who were unaware of them. However, a study showed that there was no significant correlation between the presence of complications and self-care [34].

There was a correlation between the presence of other chronic diseases besides diabetes and mean self-care agency scores. Those who had no other disease besides diabetes were observed to have higher self-care agency scores than those who had other diseases. No significant correlation was found between the presence of other diseases and self-care agency scores in a number of studies [18] [20] [35]. However, a study made with patients on peritoneum dialysis showed that those who had a chronic disease had higher self-care agency scores [46].

There was no statistically significant correlation between regular use of medication and mean self-care agency scores. Similar to the result of our study, no significant correlation was observed in another study between regular use of medication and mean self-care agency score [18]. To be able to achieve glycemic control, individuals with diabetes should pay regular check-up visits, monitor their blood glucose level, adhere to insulin and drug therapies, and organize their diet and exercises [46].

A correlation was found between regular checking of blood sugar and mean self-care agency scores of the participating subjects. Those who had their blood sugar checked regularly were seen to have higher self-care agency scores than those who failed to do so. Similar to the result of our study, another study also found that self-care affected glycemic control [34]. It was found in a different study that there was a significant correlation between self-care behaviors such as following a diet and having blood sugar measured/monitored, and compliance with medication [45]. Another study made with diabetic patients found that from the diabetic self-care activities, the patients performed mostly foot care and blood sugar measurement in the last one week and the least they performed was physical activity [47]. To be able to achieve glycemic control, individuals with diabetes should pay regular check-up visits, monitor their blood glucose level, adhere to insulin and drug therapies, and organize their nutrition and exercises [46]. Patients were found to prefer blood glucose monitoring, not only because it is more reliable and informative, but also because it makes them feel they assume an active role in the treatment of diabetes, gives them motivation and enables continuation of glycemic control [48]. According to this result, it is an expected situation that the subjects have good self-care behaviors.

A significant correlation was found between the compliance with diet and mean self-care agency scores of the subjects with type 2 diabetes. Those who adhered to their diets had higher self-care agency scores than those who failed to do so. A study showed that patients with type 2 diabetes had better compliance with their diets. Compliance with diet is one of the self-care behaviors [49]. In another study, no significant correlation was observed between compliance with diet and self-care agency score [18]. Checking blood sugar and compliance with diet are among the self-care activities [42].

Self-care in diabetes is an evolutionary process improving knowledge and awareness 
through learning about diabetes with its complex nature in a social setting. The diabetic self-care activities involve the acts of people who are at risk in terms of diabetes towards managing diabetes in a successful manner [42]. In the present study, the mean self-care agency score of diabetic patients was $83.85 \pm 17.87$. In many studies the mean self-care agency scores of patients have been found to be at moderate levels [35] [36] [50]. A study found that $28.2 \%$ of the patients with type 2 diabetes experienced problems with self-care [51]. Effective self-care behaviors, increased knowledge and improved compliance with medication have been shown to be associated with improved diabetes [45].

A significant positive correlation was found in this study between activities of daily living and self-care agency. A study showed that self-care was an important factor for patients in performing their activities of daily living and they needed adequate self-care agency to be able to perform these activities of daily living [52] and adults with type 2 diabetes stressed in another study that they needed instrumental help for their self-care behaviors [53]. Similar to the result of our study, other studies have also reported that the relationship between self-care agency, quality of life and activities of daily living is significant in patients with chronic diseases [54] [55]. It was found in the present study that the patients had sufficient self-care agency to be able to perform their activities of daily living.

\section{Conclusion and Suggestions}

The following results have been obtained in this study which was conducted to determine the effect of activities of daily living on self-care agency in patients with type 2 diabetes:

-Most patients the entire diabetic subjects were independent as per Katz ADL and more than half of them as per IADL;

-The mean self-care agency score of the patients was $83.85 \pm 17.87$;

-Marital status and education were significantly correlated with the self-care agency score;

-From the disease-related characteristics of the patients, duration of the disease, willingness to receive further education on diabetes, awareness of disease complications, presence of chronic disease, regular checking of blood sugar and compliance with diet had an impact on self-care agency;

-There was a significant correlation between activities of daily living and self-care agency.

In the light of these results, we can suggest that the self-care agency activities of diabetic patients should be supported to enable them to perform their activities of daily living independently; educational programs should be organized concerning self-care by taking into consideration personal characteristics such as age, marital status and education and disease-related characteristics such as disease complications and presence of any other disease besides diabetes; and nurses should support and regularly monitor diabetic persons. Since diabetes is a frequently seen disease in communities, we can also suggest that nurses should identify persons that are ill and at risk and organize planned educational programs for them. 


\section{Conflict of Interests}

The authors declare that they have no conflict of interests.

\section{Authors' Contribution}

This study was designed by Neslihan İstek and Papatya Karakurt. Patient selection and data collecting were organized by Neslihan İstek and Papatya Karakurt. Statistical analyses were done by statistical expert. The paper was written by Neslihan İstek and Papatya Karakurt.

\section{References}

[1] T. R. Ministry of Health Public Health Agency of Turkey (2014) Turkey Diabetes Program 2015-2020. The Kuban Printing Publishing, Ankara.

[2] T. R. Turkey Ministry of Health Diabetes Prevention and Control Program (2011) General Directorate of Primary Health Care. Anil Press, Ankara.

[3] Karadakovan, A. and Eti Aslan, F. (2014) Internal and Surgical Care. 3rd Edition, Academy Bookstore, New York.

[4] International Diabetes Federation (2008) International Curriculum for Diabetes Health Professional Education. B-1000 Brussels, 30-45.

[5] Şahin, Z.A. and Şahin, M. (2014) Adaptatıon of Elderly Diabeticpatients to Activities of Daily Life and Evaluation of Their Self-Care Abilities. Turkish Journal of Geriatrics, 17, 278-284.

[6] Gümüş, K. and Ünsal, A. (2014) Evaluation of Daily Living Activities of the Individuals with Osteoarthritis. Turkish Journal of Osteoporosis, 20, 117-124. http://dx.doi.org/10.4274/tod.93723

[7] Yildırım, Y.K. and Karadakovan, A. (2004) The Relationship between Fear Offalling, Activities of Daily Living and Quality of Life among Elderly Individuals. Turkish Journal of Geriatrics, 7, 78-83.

[8] Bulucu, G.D. and Ünsal, A. (2014) Care Needs of the Elderly People Who Lived at Home in a Neighborhood with Low Socio-Economic Level. Gümüşhane University Journal of Health Sciences, 3, 577-587.

[9] Tel, H., Tel, H. and Sabancioğullari, S. (2006) Status of Maintenance of Activities of Daily Living and Experience of Loneliness in Elder than 60 Years Old Living at Home and in İnstitutions. Turkish Journal of Geriatrics, 9, 34-40.

[10] Mollaoğlu, M. (2011) Disability, Activities of Daily Living and Self-Efficacy in Dialysis Patients. TAF Preventive Medicine Bulletin, 10, 181-186.

http://dx.doi.org/10.5455/pmb.20110123102619

[11] Akça, A.S.D., Saraçli, Ö., Emre, U., Atasoy, N., Güdül, S., Banu, B.Ö., et al. (2014) Relationship of Cognitive Functions with Daily Living Activities, Depression, Anxiety and Clinical Variablesin Hospitalized Elderly Patients. Archives of Neuropsychiatry, 51, 267274.

[12] Enç, N. (2014) Diyabetes Mellitus. In: Enç, N., MSc, N. and Alkan, H.Ö., Eds., Internal Medicine Nursing, Nobel Tip Kitabevleri, Istanbul, 281-289.

[13] Sabuncu, N., Babadağ, K., Taşocak, G. and ve Atabek, T. (1996) Hemşirelik Esaslari. Açiköğretim Fakültesi Yayınlari No. 225. 
[14] Gao, J., Wang, J., Zhu, Y. and Yu, J. (2013) Validation of an Information-Motivation Behavioral Skills Model of Self-Care among Chinese Adults with Type 2 Diabetes. BMC Public Health, 13, 100. http://dx.doi.org/10.1186/1471-2458-13-100

[15] Zhou, Y., Liao, L., Sun, M. and He, G. (2013) Self-Care Practices of Chinese Individuals with Diabetes. Experimental and Therapeutic Medicine, 5, 1137-1142.

[16] Hernandez-Tejada, M.A., Campbell, J.A., Walker, R.J., Smalls, B.L., Davis, K.S. and Egede, L.E. (2012) Diabetes Empowerment, Medication Adherence and Self-Care Behaviors in Adults with Type 2 Diabetes. Diabetes Technology \& Therapeutics, 14, 630-634. http://dx.doi.org/10.1089/dia.2011.0287

[17] Ayele, K., Tesfa, B., Abebe, L., Tilahun, T. and Girma, E. (2012) Self Care Behavior among Patients with Diabetes in Harari, Eastern Ethiopia: The Health Belief Model Perspective. PLoS ONE, 7, e35515. http://dx.doi.org/10.1371/journal.pone.0035515

[18] Aksel, Ş. (2010) Determination the Self-Care Agency and Home Care Needs of Patients Who Has Chronic Diseases. Master's Thesis, Institute for Near East Universityof Health Sciences, Nicosia.

[19] Düzöz, G.T., Çatalkaya, D. and Uysal, D.D. (2009) The Evaluation of the Self-Care of Patients with Type 2 Diabetes Mellitus. Yeni Tip Dergisi, 26, 210-213.

[20] Karakurt, P., Hacıhasanoğlu Aşılar, R. and Yıldırım, A. (2013) Evaluation of the Self-Care Agency and Perceived Social Support in Patients with Diabetes Mellitus. Adnan Menderes University Faculty of Medicine Journal, 14, 1-9.

[21] American Diabetes Association (2013) Standards of Medical Care in Diabetes. Diabetes Care, 36, 11-66. http://dx.doi.org/10.2337/dc13-S011

[22] Sürücü, H.A. (2014) Diabetes Self-Management Education, Group-Based Education and Individual Education. Dokuz Eylul University School of Nursing Electronic Journal, 7, 4651.

[23] Katz, S., Downs, T.D., Cash, H.R. and Grotz, R. (1970) Progress in Development of the İndex of ADL. Oxford Journal, 10, 20-30. http://dx.doi.org/10.1093/geront/10.1_part_1.20

[24] Lawton, M.P. and MB, E. (1969) Assessment of Older People: Self-Maintaining and İnstrumental Activities of Daily Living. Gerontologist, 9, 179-186. http://dx.doi.org/10.1093/geront/9.3_Part_1.179

[25] Kearney, B.Y. and Fleischer, B.J. (1979) Development of an Instrument to Measure Exercise of Self-Care Agency. Research in Nursing \& Health, 2, 25-34. http://dx.doi.org/10.1002/nur.4770020105

[26] Nahcivan Özkan, N. (1993) Self-Care and the Influence of Family Environment on the Health of Young People. PhD Thesis, Istanbul University, İstanbul.

[27] Nahcivan Özkan, N. (2004) A Turkish Language Equivalence of the Exercise of Self-Care Agency Scale. Western Journal of Nursing Research, 26, 813-824. http://dx.doi.org/10.1177/0193945904267599

[28] Toljama, M. and Hentinen M. (2001) Adherence to Self-Care and Glycaemic Control among People with İnsülin-Dependent Diabetes Mellitus. Journal of Advanced Nursing, 34, 780-786. http://dx.doi.org/10.1046/j.1365-2648.2001.01808.x

[29] Gül, A., Üstündağ, H. and Zengin, N. (2010) The Evaluation of Self-Care Agency in Renal Transplant Patients. General Medical Journal, 20, 7-11.

[30] Yurtsever, S. and Kuyurtay, F. (2005) Fatigue and Self-Care in Hemodialysis Patients. Journal of Nephrology Nursing, 2, 26-32.

[31] Akyol, A.D. and Karadakovan, A. (2002) Examined the Effect of These Variables on the 
Quality of Life and Self-Care in Patients Undergoing Hemodialysis. Ege Journal of Medicine, 2, 97-106.

[32] Velioğlu, P. (2012) Concepts and Theories in Nursing. Alaş offset, Istanbul.

[33] Yanık, Y.T. (2011) Evaluation of Self-Efficacy Levels of Patients with Type 2 Diabetes. Nursing Unpublished Master's Thesis, Trakya University Institute of Health Science Nursing Department of Internal Medicine, Edirne.

[34] Gao, J., Wang, J., Zheng, P., Haardörfe, R., Kegler, M.C., Zhu, Y. and Fu, H. (2013) Effects of Self-Care, Self-Efficacy, Social Support on Glycemic Control in Adults with Type 2 Diabetes. BMC Family Practice, 14, 66. http://dx.doi.org/10.1186/1471-2296-14-66

[35] Altay, G. and Avci, İ.A. (2009) The Relation between the Self Care Strength and Life Satisfaction of the Elderly Living in Nursing Home. Dicle Dicle Medical, 36, 275-282.

[36] Uğurlu, N., Bolat, M. and Erdem, S. (2010) Determination of Factors Affecting Self-Care in the Elderly. Journal of Psychiatric Nursing, 1, 56-62.

[37] Hacıhasanoğlu, R. and Yıldırım, A. (2009) Evaluation of Quality of Life and the Power of Self-Care in Hemodialyiss Patients. Ege University School of Nursing Journal, 25, 87-100.

[38] Tel, H., Güler, N. and Tel, H. (2011) Continue Their Activities of Daily Living Condition and Quality of Life of the Elderly at Home. Journal of Nursing Research Development, 2, 59-67.

[39] Özkan, S. and Durna, Z. (2006) Insulin Dependent Diabetics to Determine the Self-Care. Ege University School of Nursing Journal, 22, 121-135.

[40] Cengiz Mand Yavuzer, S. (2015) Oral Antidiabetic Therapy in Diabetes. Turkey Private Clinic Family Medicine Journal, 6, 10-13.

[41] Işık, S., Delibaşı, T., Berker, D., Aydın, D. and Güler, S. (2009) Eart Disease in Diabetes Management. Anatolia Journal of Cardiology, 9, 238-47.

[42] Shrivastava, S.R., Shrivastava, P.S. and Ramasamy, J. (2013) Role of Self-Care in Management of Diabetes Mellitus. Journal of Diabetes \& Metabolic Disorders, 12, 14. http://dx.doi.org/10.1186/2251-6581-12-14

[43] Dunbar, S.B., Butts, B., Reilly, C.M., Gary, R.A., Higgins, M.K., Ferranti, E.P., Culler, S.D. and Butler, J. (2014) A Pilot Test of an İntegrated Self-Care İnterventıon for Persons with Heart Failure and Concomitant Diabetes. Nursing Outlook, 62, 97-111. http://dx.doi.org/10.1016/j.outlook.2013.09.003

[44] Avdal, E.Ü. and Kızılc1, S. (2010) Diabetes and Self-Care Deficit Nursing Theory’s Concept Analysis. Dokuz Eylul University School of Nursing Electronic Journal, 3, 164-168.

[45] Hernandez-Tejada, M.A., Campbell, J.A., Walker, R.J., Smalls, B.L., Davis, K.S. and Egede, LE. (2012) Diabetes Empowerment, Medication Adherence and Self-Care Behaviors in Adults with Type 2 Diabetes. Diabetes Technology \& Therapeutics, 14, 630-634. http://dx.doi.org/10.1089/dia.2011.0287

[46] Bakoğlu, E., Şekerci, K., Yaman, S. and Çevik, M. (2009) Peritoneal Dialysis Patients in Self-Care. Firat Health Service Journal, 4, 65-78.

[47] Watkins, Y.J., Quinn, L.T., Ruggiero, L., Quinn, M.T. and Choi, Y.K. (2013) Spiritual and Religious Beliefs and Practices. and Social Support's Relationship to Diabetes Self-Care Activities in African Americans. Diabetes Education, 39, 231-239. http://dx.doi.org/10.1177/0145721713475843

[48] Erol, Ö. (2013) Endocrine System Diseases and Maintenance. In: Durna, Z., Ed., Internal Medicine Nursing, Academy of Press and Publication, Istanbul, 231-253.

[49] Johnson, M.D., Anderson, J.R., Walker, A., Wilcox, A., Lewis, V.L. and Robbins, D.C. 
(2013) Common Dyadic Coping Is Indirectly Related to Dietary and Exercise Adherence via Patient and Partner Diabetes Efficacy. Journal of Family Psychology, 27, 722-730. http://dx.doi.org/10.1037/a0034006

[50] Mollaoğlu, M., Fertelli, T.K. and Tuncay, F.Ö. (2006) Evaluation of Self-Care in Patients with Multiple Sclerosis. Ataturk University School of Nursing Journal, 9, 1-7.

[51] Saleh, F., Mumu, S.J., Ara, F., Hafez, M.A. and Ali, L. (2014) Non-Adherence to Self-Care Practices \& Medication and Health Related Quality of Life among Patients with Type 2 Diabetes: A Cross-Sectional Study. BMC Public Health, 14, 431.

http://dx.doi.org/10.1186/1471-2458-14-431

[52] Flensner, G. and Lindergrona, C. (1999) The Cooling-Suit: A Study of Ten Multiple Sclerosis Patients' Experience in Daily Life. Journal of Advanced Nursing, 29, 1444-1453. http://dx.doi.org/10.1046/j.1365-2648.1999.01032.x

[53] Mayberry, L.S. and Osborn, C.Y. (2012) Family Support, Medication Adherence and Glycemic Control among Adults with Type 2 Diabetes. Diabetes Care, 35, 1239-1245. http://dx.doi.org/10.2337/dc11-2103

[54] Mc Laughlin, J. and Zeeberg, I.B. (1993) Self Care and Multiple Sclerosis: A View from Two Cultures. Social Science and Medicine, 37, 315-329. http://dx.doi.org/10.1016/0277-9536(93)90263-4

[55] Evans, E. and Wickstrom, B. (1999) Subjective Fatigue and Self Care in İndivuduals with Chronic İllness. Medsurg Nursing, 8, 363-372.

Submit or recommend next manuscript to SCIRP and we will provide best service for you:

Accepting pre-submission inquiries through Email, Facebook, LinkedIn, Twitter, etc. A wide selection of journals (inclusive of 9 subjects, more than 200 journals)

Providing 24-hour high-quality service

User-friendly online submission system

Fair and swift peer-review system

Efficient typesetting and proofreading procedure

Display of the result of downloads and visits, as well as the number of cited articles Maximum dissemination of your research work

Submit your manuscript at: http://papersubmission.scirp.org/

Or contact jdm@scirp.org 